\title{
Writing and publishing a scientific paper
}

\author{
Fritz Scholz ${ }^{1}$ (1)
}

Received: 17 November 2021 / Accepted: 3 January 2022 / Published online: 11 January 2022

(c) The Author(s) 2022

\begin{abstract}
This text is designed to give the reader a helping hand in writing a scientific paper. It provides generic advice on ways that a scientific paper can be improved. The focus is on the following ethical and non-technical issues: (1) when to start writing, and in what language; (2) how to choose a good title; (3) what should be included in the various sections (abstract, introduction, experimental, results, discussion, conclusions, and supporting information (supplementary material); (4) who should be considered as a co-author, and who should be acknowledged for help; (5) which journal should be chosen; and (6) how to respond to reviewers' comments. Purely technical issues, such as grammar, artwork, reference styles, etc., are not considered.
\end{abstract}

\section{Graphical abstract}

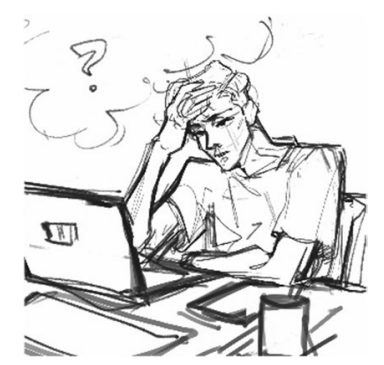

Keywords Publishing $\cdot$ Journal $\cdot$ Science $\cdot$ Ethics $\cdot$ Peer review

“Work, finish, publish” (Michael Faraday) [1]. ${ }^{1}$

\section{Introduction}

The task of writing a scientific paper usually befalls young researchers quite early in their bachelor, masters or $\mathrm{PhD}$ degree programs. In most cases, the candidates know very little about the publishing process, which involves a complex combination of historical traditions and modern innovations. Guidebooks are of course available, but these tend to focus on purely technical issues, and miss the interpersonal nuances that are so daunting for the beginner. In any case, the technical issues are normally not the main problem for

Fritz Scholz

fscholz@uni-greifswald.de

1 Universität Greifswald, Greifswald, Germany computer-literate students, so I avoid them in this document. Instead I present my personal views on the overall process, and leave it to the reader to evaluate them.

Long experience has taught me that there are many ways of writing a successful paper, but nevertheless some general principles can be identified. In what follows, all my suggestions are informed by my experience as the editor-in-chief of two international journals, the Journal of Solid State Electrochemistry for 25 years, and ChemTexts-The Textbook Journal of Chemistry for 7 years. I have also been the editor of the series Monographs in Electrochemistry, as well as various reference books and textbooks.

Looking back at history, the communication of scientific results in specialist journals is a rather recent development: its origins date back to the second half of the seventeenth

\footnotetext{
${ }^{1}$ It is on record that when a young aspirant asked Faraday the secret of his success as a scientific investigator, he replied: "The secret is comprised in three words—work, finish, publish."
} 
century. In 1665, the Journal des sçavans started in France, while the Philosophical Transactions of the Royal Society began in Great Britain. Before that time, it was common to publish new findings in books. However, the increasing pace of scientific developments, as well as the increasing number of people who were devoting their lives to science, required a more efficient and faster form of communication. For this to be achieved, journals proved to be very successful. The history of scientific journals cannot be traced here, but I recommend the book The Scientific Journal by Alex Csiszar [2].

Scientific communication requires a common language that is shared by the author and the reader. Michael D. Gordin has described in his book Scientific Babel [3] how, over the last few centuries, scientific communication has gradually shifted from Latin to English. The author also pays detailed attention to the French, German and Russian languages, which played important roles in the nineteenth and twentieth centuries. These languages retain their importance for scientists, because they contain the foundational texts of many important branches of science.

\section{When to start writing a manuscript}

It is trivial to say that one should write a manuscript only when one has new results to communicate. But new results do not appear suddenly and without ambiguity. Rather, they tend to accumulate gradually over time, and require repeated contextualisation to be fully appreciated. This begs the question, at what point should one publish?

Answering this question is difficult. Students certainly need to discuss the matter with their supervisors, who have the necessary experience and far-sightedness. Beginners often wildly underrate or overrate their data. Realistically, however, all scientific publication is a compromise between "publishing too late" and "publishing too early".

"Publishing too late" (or never) is a well-known fault of some overcautious individuals, who withhold their data from public scrutiny because they are not satisfied with its accuracy and completeness. Although this demonstrates their high ethical standards as regards their personal participation in the scientific process, it also reveals an indifference to the social value of their data and the financial costs to others of having to reproduce their results. In the final analysis, tax-payers' money that is spent on unpublished work is wasted money, and this raises questions of probity. (In the case of industrial research, contractual confidentiality may also restrict publication, but that is a problem I cannot discuss here.)

"Publishing too early" is a fault of some reckless individuals who have scant regard for the integrity of the scientific process. The institutional pressure to publish papers and the competition for scarce funds are the main causes of this. Nowadays, pollution of the scientific literature by worthless, irreproducible or sloppy work is an increasing and serious problem. Here I can only plead with colleagues of all ages: please do not be tempted by the short-term advantages of overpublication. The benefits are illusory, and the damage is untold. With the advent of mass data storage, published papers are effectively immortal, and sooner or later bad work (and its creators) will be found out.

Of course, "publishing too early" is most tempting for the beginner, and the problem becomes critical when the supervisor is also overambitious. If the supervisor pressurizes the student to publish uncooked results, then the student has a big problem! Now, many universities have introduced 'thesis committees' consisting of the primary supervisor plus two or three additional members. These committees can provide valuable advice with respect to timeliness of publishing and they may also mitigate conflicts between the student and their main supervisor, if they happen to occur.

Personally, I have been an ombudsman at my university, and I am pleased to say that such conflicts can be resolved amicably by careful and trustful discussions between all parties. But I fear that global science has a problem with this issue.

The whole question of when to start writing cannot be answered by a simple prescription, and depends to a large extent on the personalities of the individuals concerned. My personal advice is to start writing as soon as the main results become discernible. Writing down the first tranche of clear and reliable results is a useful discipline which indicates what has been achieved and what experiments remain to be done. If you delay writing until you think that all the required experiments have been completed, then you will be sadly disappointed. You will discover that much has been omitted, and then you will have to start again with certain crucial experiments. It goes without saying that co-authors should be involved very early in the writing.

\section{In what language should the paper be written?}

What language to use is rather obvious. If you want to be understood worldwide, then you must publish in English. In 2021, there were around 1.35 billion people, scattered over many countries, who spoke English as a first or second language. If you are not a native English speaker, then I strongly recommend that you start to write in English. Do not write in your native language with the vague notion of translating it later into English. This is always bad policy, because you will certainly find it more difficult to translate your text into English than to compose it from scratch. 
Assuredly, this demands a reasonable command of English. But there are practical steps that you can take to help you along the way.

To achieve a sufficient command of English, you should read as many well-written(!) scientific papers in English as possible. For technical English, try to focus on papers written by native English speakers. However, do not limit yourself to scientific papers, but also read English stories and novels, or any other writings, that can expand your knowledge of English. You should also try to distinguish the different styles (scientific, colloquial, etc.) and avoid mixing them in your own writing.

At this point I suggest the book The Chemist's English [4] written by Robert Schoenfeld, and his paper "Say it in English, please" [5]. Schoenfeld was editor-in-chief of the Australian Journal of Chemistry. One trick that I have found very effective for improving my written English is to translate the draft manuscript back into my native language (in my case German). For many years I did this for publications in Angewandte Chemie, a journal that is published both in English and German, and these back translations frequently revealed the weaknesses in my English.

Concerning written text, I have some further advice which is not specific to the English language: first of all, write clearly and understandably! The eminent physicist Carl Wagner (1901-1976) famously wrote "Any fool can think and write something complicated" ("Jeder Dumme kann etwas Kompliziertes denken und schreiben") [6]. Always remember these wise words! Whenever you write a very complicated phrase, ask yourself, do you really understand what you have written? Very often, complicated constructions are the result of an insufficient understanding, or represent an attempt at "hedging" i.e. attempting to disguise the omission of certain facts which might otherwise conflict with the overall claims being made.

In the same book, Wagner also wrote "It is a very special art to speak understandably about subjects when they are not yet completely known". With regard to clear and understandable language, I should also like to give a serious warning regarding the misuse of certain words and phrases that express uncertainty: "possibly", "probably", "may be an indication of", "seems to be", "cannot be excluded", "it is reasonable to assume", etc. It is possible that these constructions may be justified in certain circumstances, but more often than not they hide a lack of understanding, and trigger alarm bells in the minds of readers. Whenever you write these phrases, ask yourself, are they necessary, are they well-reasoned? I have seen manuscripts full of such vague phrases, and it was clear that they were more or less worthless!

For the language of a paper to be intelligible, it is also necessary that a well-defined terminology is used. The terms have to be internationally accepted (e.g. by IUPAC) and have to be used consistently. It is not good to operate with several synonyms, but one and the same should be used throughout.

\section{The structure of a scientific paper}

Usually, scientific papers are structured in the following subsections: (1) title, (2) name of authors and their affiliation(s), (3) keywords, (4) graphical abstract, (5) abstract, (6) introduction, (7) experimental part, (8) results and discussion, (9) conclusions, (10) acknowledgements, (11) references, (12) list of figure captions, (13) figures. Most journals offer publication of 'supporting information' (or 'supplementary material'): these supplements are not part of the main paper, but usually constitute a depository for data, figures, tables, mathematical derivations, etc. which the reader may like to consult for a deeper understanding, which, however, are not vital for a general understanding of the paper. I always prefer to put as much as possible into the main paper, and restrict supplementary information to items which are really of less significance. Many journals provide templates, which you should use. In these templates, the order of items may differ from that given above. You should always adhere strictly to the guidelines of the journal. Some details relating to the subsections of a paper are described below.

\section{The title}

The title is the entrance door to your paper. Reading the title, many people make the decision whether to enter the document or walk away. According to Thomson's Web of Science, about $27 \%$ of natural science papers are uncited after 5 years, most likely because they are unread, or undiscovered by search engines. To attract interest, the title of a paper needs to be as short as possible, but as long as necessary. It should also contain some searchable terms for easy computer recognition. Certainly, the title also needs to indicate the very essence of the paper. Prior to the advent of computers, it was customary to use titles like "Studies in phosphorus chemistry. Part XII."! What on earth does that tell you? Nothing about the specific contents, that's for sure. Luckily, the time of such absurdities is over.

Phrasing the title of a scientific paper is hard work, and usually the final choice will emerge only after long consideration. It is my personal view that authors should think about the title at the very beginning of writing a manuscript. Since the title reveals the essence, a well-chosen title can set the tone for the entire manuscript. And it goes without saying that the title can still be modified many times as the manuscript mutates into its final form. 


\section{The keywords}

Most journals request a list of keywords. These are important for the classification of the paper in information systems. Think about the terms that best characterise the content of your paper. However, try to avoid newly created terms or abbreviations. Although an overlap between title terms and keywords is unavoidable, the latter should provide additional information.

\section{The abstract}

Following the title, the abstract is the most important device for attracting the attention of readers. Personally, I have always advocated writing the first draft of the abstract before writing the remainder of the text. This forces the author to identify the principal achievements at an early stage. Like the title, the abstract needs to be as short as possible and as long as necessary. Its function is to summarize all the main results. I know that many experienced colleagues disagree with my suggestion of writing the first draft of the abstract before writing the main body of the text. However, my suggestion is not meant to be an apodictic rule. You must find out what best suits you.

Drafting the title and abstract at an early stage presupposes that you already have a clear picture of your achievement. If you do not have that clear picture, then a good suggestion is to arrange all your diagrams and tables in a logical sequence, and then write the text around that.

The abstract needs to contain as much quantitative information as possible. If you have new and significant data, give them in the abstract!

\section{The introduction}

The introduction should state the motivation and the aim of the presented research and refer to all relevant literature. If the paper is intended for a specialised journal, avoid rehashing simple textbook knowledge, as you can assume that expert readers will already be acquainted with it. In more general journals, some wider introductory remarks may be necessary.

When you discuss earlier works in your field, do not focus purely on their shortcomings. Make sure that you acknowledge their achievements. Be fair in your presentation. Cite all relevant papers, at least the most important ones. Do not overcite your own papers.

At the end of the introduction, state what you have achieved and what you will present in the paper. Do not repeat the abstract. This is important for the entire paper: avoid repetitions!

\section{The experimental part}

This part should contain sufficient experimental details (chemicals, instruments, methods, etc.) for your work to be reproduced in another laboratory. If certain procedures or techniques have previously been published by you, or others, you may refer to those papers without repeating the details. However, the reference has to be accessible. I have seen papers in which the author wrote "the technique is described in Ref. X". When reading Ref. X, I found the remark "the technique is described in Ref. Y", and so forth until I gave up searching! This is unacceptable.

\section{The results and discussions}

In the past, many journals have demanded that the results and discussion be reported separately. Some journals still demand this. Especially in the case of highly multidisciplinary work it is necessary to present first the results of the different disciplines, followed by a joint discussion referring to all the disciplines. However, if possible, I advocate providing the results and discussion simultaneously, since the combined text is easier to understand.

The most important point in writing the results and discussion section is logical consistency. The most frequently seen weakness appears when authors forego logical consistency and instead provide a chronological history of their experiments. This is often copied from laboratory notebooks. One then finds phrases like "first we thought that $\mathrm{x}$ may be the reason for $\mathrm{y}$, and we performed the following experiments... then it turned out that $\mathrm{y}$ has nothing to do with $\mathrm{x}$, and we supposed that $\mathrm{z}$ might cause the observed effect. Then we did this, and later we did that, and in the end...". Such historical summaries are extremely tedious for the reader, and may even be misleading.

In results and discussion, it is essential to illustrate the results with clear reference to figures and tables, and to arrange the results within a logical framework. Figures, having captions, and tables, having headings, should be understandable without reading the detailed text.

\section{The conclusions}

The most frequent fault is the copying of an abstract, or the minor modification of an abstract, without any reference to the context of the results. The abstract does not require justification of the work: the conclusions certainly do. The conclusions have to provide new insight into a field of research, and this must be explained. The best writers will also indulge in some speculations about future work. 
These should open the readers' eyes to novel and unexpected applications of the findings.

When you have finished writing a manuscript, leave it for some time untouched, and then read it again after some days or weeks. You will discover that a fresh reading reveals flaws, repetitions, typos, etc., which you missed the first time around. You should also use that time to circulate the document among trusted friends and colleagues who may act as internal reviewers before external submission. You will be surprised what typos your friends find! The blindness of authors to their own typos is legendary. The modern spellcheckers of computer systems do not prevent all typos, but they are helpful. (They may even introduce further errors, if you are not attentive).

\section{Who should be co-authors and who should be acknowledged for help?}

The ethical guidelines of most scientific funding organisations (e.g. Deutsche Forschungsgemeinschaft (DFG)/German Research Council [7]) demand that everybody who has a distinct share, be it intellectual or experimental, in a paper has to be listed as a co-author. Any "honorary" coauthorship is not allowed! This is a clear statement, but a lot of questions may arise in specific cases. Since I cannot say it in a better way, I cite here from the DFG guidelines:

Guideline 14: Authorship

- An author is an individual who has made a genuine, identifiable contribution to the content of a research publication of text, data or software. All authors agree on the final version of the work to be published. Unless explicitly stated otherwise, they share responsibility for the publication. Authors seek to ensure that, as far as possible, their contributions are identified by publishers or infrastructure providers such that they can be correctly cited by users.

Explanations:

The contribution must add to the research content of the publication. What constitutes a genuine and identifiable contribution must be evaluated on a case-by-case basis and depends on the subject area in question. An identifiable, genuine contribution is deemed to exist particularly in instances in which a researcher-in a research-relevant way-takes part in

- the development and conceptual design of the research project, or

- the gathering, collection, acquisition or provision of data, software or sources, or
- the analysis/evaluation or interpretation of data, sources and conclusions drawn from them, or

- the drafting of the manuscript.

If a contribution is not sufficient to justify authorship, the individual's support may be properly acknowledged in footnotes, a foreword or an acknowledgement. Honorary authorship where no such contribution was made is not permissible. A leadership or supervisory function does not itself constitute co-authorship.

At some educational institutions, the rules for submitting a $\mathrm{PhD}$ thesis demand a certain number of submitted or published papers. Unfortunately, this occasionally leads to a sharing of authorship among two or more candidates, so that each of them reaches the desired number, although neither of them has a proper share in all the papers. This is unethical and is strongly condemned.

A very crucial point is that all co-authors must give their clear consent to the submission of the manuscript. Nowadays, most journals send emails to the co-authors informing them about the submission. However, this does not liberate principal authors from the moral imperative of sending their co-authors copies of the manuscript in advance of publication and asking for their consent! Similar advice applies to acknowledgements. Who would be happy about an acknowledgement in a paper that they disagree with?

\section{Which journal should be chosen?}

The manuscript should be submitted to a journal which is devoted to the branch of science concerned. Usually there are several journals available so authors need rational criteria for making a choice. Experienced authors typically decide on the basis of publishers' reputations (journal citation metrics) or personal connections (networks of esteem). Nowadays, scientific information systems even make it possible to unearth obscure papers published in "wrong" journals, on the basis of the title, keywords and abstract. However, indifference to journal choice is not recommended as a career strategy!

Citation metrics have a history of about 200 years [8]. However the modern infatuation with citation metrics has been driven by their uncritical adoption by research organisations and promotion committees in making decisions about funding and promotion.

In 2012, the San Francisco Declaration on Research Assessment (DORA; https://sfdora.org) criticized the use of "impact factors" for evaluating the merits of scientists. Since then, the criticism has intensified (see, e.g., [9-13]). Authors are now in a serious conflict situation: should they follow 
the metrics, or should they choose a journal according to other quality measures? This question is difficult to answer.

What are other quality measures? In my view, one of the most important is the quality of its reviewers and their reports. Those reports are the best which are competent, fair and helpful. Journals which provide such reports should certainly be considered. But these high-quality journals can only be identified by long experience.

Ultimately, neither the Impact Factor nor the CiteScore of a journal is an unambiguous measure of the quality of a single paper. So students should not feel upset when their papers appear in low index journals, nor should they feel triumphant when their papers appear in high index journals.

In all cases authors should beware of publishing in predatory journals (https://en.wikipedia.org/wiki/Predatory_publi shing). Open access predatory journals publish manuscripts without serious review. They publish only for money.

Now, a final word about "open access" publishing: this is certainly the best way to disseminate scientific information; however, only if the journals operate a strict peer review. Some scientific publishers (e.g. Springer Nature, https:// www.springernature.com/gp/open-research/institutionalagreements) also have international agreements with universities and institutions to pay the costs of publishing.

\section{How to respond to reviews of submitted manuscripts}

It is very interesting to learn how the "peer review system" emerged and I suggest that students read about it in a paper by Csiszar in Nature [14]. Nowadays, when a manuscript is submitted to a reputable journal, it will first be read by members of the editorial board, who decide whether it should be sent out to referees (reviewers) or sent back to the authors. If serious deficiencies are identified then it is senseless to bother reviewers.

When you receive the reviews of your manuscript, normally at least two or three, you need to know what to do with them. In any event, you should be self-critical: if you get the report "publish as is" or a similar positive evaluation, do not image that your manuscript is perfect. Possibly the reviewer was not competent or was very sloppy in assessing your manuscript. Believe the positive evaluations only when you get two or three of them!

The other extreme may be a report saying "this is a very weak manuscript that should not be published", without giving specific criticism. Such a report is not helpful and the editor must take the blame for accepting it and passing it to the author. Harsh criticisms require detailed justification, just as extraordinary claims require extraordinary proof.

Fortunately, most reviewers take their job very seriously and deliver clear and detailed reports. You, the author, should always presume that the reviewers are trying to help you to improve your manuscript. They are not your enemy, but on your side, and they are fair. If you do identify clear signs of unfairness, then you should turn to the editor and ask for further reports. It often happens that the first reaction of an author is "oh, this reviewer has completely misunderstood me" and then starts to write a long rebuttal to the editor, explaining all the misunderstandings! However, since reviewers are experts in their field, the author should realize that a likelier explanation of a poor review is the poor quality of the manuscript!

Of course, it really may be true that a reviewer has misunderstood a manuscript. However, in most cases, it is my experience as an editor that the misunderstandings result from deficiencies of the manuscript, such as confusing phrases. Therefore, it is my advice to ask yourself how this misunderstanding could have happened. Do not blame the reviewer; think about your own text!

When you prepare the revised manuscript, follow carefully the advice of the reviewers. In the revised manuscript, you should highlight all the revised parts, which makes it easy for the editor and reviewers to see how you have responded. Your revised manuscript also needs to be accompanied by a detailed document (rebuttal) in which you list the changes and give your explanations for the revisions. Certainly, you are not obliged to do everything as requested by the reviewers. If you have good arguments against the reviewer's proposals, bring them forward, and it will be up to the editor and reviewers to accept or to reject them.

It goes without saying that it is unacceptable to submit a rejected manuscript to another journal (sometimes even the same journal) without any revisions. This is profoundly disrespectful. When a manuscript has been rejected by a journal, you are of course free to submit it elsewhere, but you need to pay attention to the previous reviews.

\section{Conclusions}

Writing a scientific paper is an art as well as a science. With all its dry scientific data and equations, it must nevertheless provide an exciting and fascinating story, in which the leitmotif is present in all parts. It should never be boring.

Publishing scientific results is a very serious task and authors must adhere to the highest ethical standards. It is neither a game nor a routine. Always remember that a published paper will remain forever attached to your name. Do not try to split your work into several pieces to increase the number of your publications. The scientific community is already overwhelmed by a flood of second-rate "minimalist" papers. Reviewers are also inundated with reviewing requests. One solid and comprehensive paper is worth much more than five short papers with tedious repetitions. 
Acknowledgements The following colleagues have provided very valuable suggestions: Antonio Doménech-Carbó (Valencia), György Inzelt (Budapest), Sigurd Lenzen (Hannover), Michael Hermes (Berlin), Heike Kahlert (Greifswald), Uwe Schröder (Greifswald) and my wife Gudrun Scholz. I am grateful for general advice from Stephen Fletcher (Loughborough), and especially thankful to him for his elegant language editing. Wilhelmine Klamt (Greifswald) is acknowledged for having drawn the graphic abstract.

Funding Open Access funding enabled and organized by Projekt DEAL.

Open Access This article is licensed under a Creative Commons Attribution 4.0 International License, which permits use, sharing, adaptation, distribution and reproduction in any medium or format, as long as you give appropriate credit to the original author(s) and the source, provide a link to the Creative Commons licence, and indicate if changes were made. The images or other third party material in this article are included in the article's Creative Commons licence, unless indicated otherwise in a credit line to the material. If material is not included in the article's Creative Commons licence and your intended use is not permitted by statutory regulation or exceeds the permitted use, you will need to obtain permission directly from the copyright holder. To view a copy of this licence, visit http://creativecommons.org/licenses/by/4.0/.

\section{References}

1. Gladstone JH (1874) Michael Faraday. Macmillan, London, p 122
2. Csiszar A (2018) The scientific journal. The University of Chicago Press, Chicago

3. Gordin MD (2015) Scientific babel. The language of science from the fall of Latin to the rise of English. The University of Chicago Press, Chicago

4. Schoenfeld R (1985) The chemist's English. VCH, Weinheim

5. Schoenfeld R (1988) Angew Chem Int Ed Engl 27:1050-1057

6. Wagner C (1974) Methoden der naturwissenschaftlichen Forschung. Wissenschaftsverlag Bibliographisches Institut, Mannheim

7. Guidelines for safeguarding good research practice. Code of Conduct (September 2018) ISBN 978-3-96827-001-2. Deutsche Forschungsgemeinschaft, German Research Foundation, Bonn, Germany

8. Csiszar A (2017) Nature 551:163-165

9. Molinié A, Bodenhausen G (2010) Chimia 64:78-89. https://doi. org/10.2533/chimia.2010.78

10. Ernst RR (2010) Chimia 64:90. https://doi.org/10.2533/chimia. 2010.90

11. Finch A (2010) BioEssays 32:744-747

12. Curry S (2018) Nature 554:147

13. Waltman L, Traag VA (2021) F1000Research 9:366. https://doi. org/10.12688/f1000research.23418.2

14. Csiszar A (2016) Nature 532:306-308

Publisher's Note Springer Nature remains neutral with regard to jurisdictional claims in published maps and institutional affiliations. 